\title{
Validation of verbal autopsy methods using hospital medical records: a case study in Vietnam
}

\author{
Hong Thi Tran ${ }^{1,2^{*}}$, Hoa Phuong Nguyen ${ }^{3}$, Sue M. Walker ${ }^{4,5}$, Peter S. Hill ${ }^{2}$ and Chalapati Rao ${ }^{6}$
}

\begin{abstract}
Background: Information on causes of death (COD) is crucial for measuring the health outcomes of populations and progress towards the Sustainable Development Goals. In many countries such as Vietnam where the civil registration and vital statistics (CRVS) system is dysfunctional, information on vital events will continue to rely on verbal autopsy (VA) methods. This study assesses the validity of VA methods used in Vietnam, and provides recommendations on methods for implementing VA validation studies in Vietnam.

Methods: This validation study was conducted on a sample of 670 deaths from a recent VA study in Quang Ninh province. The study covered 116 cases from this sample, which met three inclusion criteria: a) the death occurred within 30 days of discharge after last hospitalisation, and b) medical records (MRs) for the deceased were available from respective hospitals, and c) the medical record mentioned that the patient was terminally ill at discharge. For each death, the underlying cause of death (UCOD) identified from MRs was compared to the UCOD from VA. The validity of VA diagnoses for major causes of death was measured using sensitivity, specificity and positive predictive value (PPV).

Results: The sensitivity of VA was at least 75\% in identifying some leading CODs such as stroke, road traffic accidents and several site-specific cancers. However, sensitivity was less than $50 \%$ for other important causes including ischemic heart disease, chronic obstructive pulmonary diseases, and diabetes. Overall, there was 57\% agreement between UCOD from VA and MR, which increased to $76 \%$ when multiple causes from VA were compared to UCOD from MR.

Conclusions: Our findings suggest that VA is a valid method to ascertain UCOD in contexts such as Vietnam. Furthermore, within cultural contexts in which patients prefer to die at home instead of a healthcare facility, using the available MRs as the gold standard may be meaningful to the extent that recall bias from the interval between last hospital discharge and death can be minimized. Therefore, future studies should evaluate validity of MRs as a gold standard for VA studies in contexts similar to the Vietnamese context.
\end{abstract}

Keywords: Validation of verbal autopsy, Causes of death, Validity, Medical record, Hospital data, Verbal autopsy, Health information, Quang Ninh, Vietnam

\section{Background}

Verbal autopsy (VA) is a method of ascertaining cause of death (COD) from information on signs/symptoms and circumstances preceding death through interviewing the deceased's caretakers [1]. VA is used as a research tool for longitudinal population studies, intervention research and epidemiological studies. It also has become a source

\footnotetext{
* Correspondence: honghsph@gmail.com

${ }^{1}$ Faculty of Fundamental Sciences, Hanoi University of Public Health, Hanoi, Vietnam

${ }^{2}$ School of Public Health, University of Queensland, Brisbane, Australia Full list of author information is available at the end of the article
}

of COD statistics at population level in some countries, providing cause-specific mortality data that can be used in priority setting for planning and policy formulation $[2,3]$. VA is the best available approach to describe the causes of death at community level or population level in countries where most deaths occur at home and without medical evidence [4].

Information on COD is crucial for measuring the health outcomes of populations and progress toward the Sustainable Development Goals $[2,5]$. In many low and middle-income countries including Vietnam, where the

(c) The Author(s). 2018 Open Access This article is distributed under the terms of the Creative Commons Attribution 4.0 International License (http://creativecommons.org/licenses/by/4.0/), which permits unrestricted use, distribution, and 
civil registration and vital statistics (CRVS) systems are dysfunctional [6-8], such information will continue to rely on VA methods [9-11]. During the past 15 years, VA methods have been used in number of studies, projects and the health and demographic surveillance system (HDSS) in Vietnam to identify mortality patterns in specific populations $[8,12-18]$. In order to establish the utility of the information on COD derived from a VA study, the validity of COD derived from VA in Vietnam needs to be assessed.

Validation is a process that compares an underlying cause of death (UCOD) derived from the VA with a reference UCOD for the same death. The reference UCOD can be derived from pathological autopsy which is considered as a "gold standard", or from clinical records which are considered as the next best alternative [19]. Chandramohan suggested that hospital diagnosis of COD which is based on defined laboratory and clinical criteria are "the only useful gold standards" available at present for validating VAs [20]. A number of VA validation studies conducted in other countries used the hospital medical records (MRs) of inpatient deaths as reference diagnoses [19, 21, 22]. However, due to cultural beliefs and traditional issues among the Vietnamese, it is a common practice for terminally ill patients to return home for the final stages of their lives $[8,11,17]$. The number of hospital deaths is very low [23], which hampers the implementation of a validation study. However, we believe that the hospital MRs of patients discharged in a terminally ill condition could provide useful information for diagnosing COD. Therefore, in order to carry out a validation study in the Vietnamese context, we adjusted the method to suit the circumstances in the country.

We conducted this study to assess the validity of COD identified from the VA methods which had been implemented in a recent study in Vietnam. Building on empirical experiences during the study fieldwork, this paper also makes recommendations on some methodological issues for implementing hospital based validation studies in Vietnam.

\section{Methods}

\section{Study setting and protocol}

We designed this validation study based upon the information extracted from a recent VA study in 12 communes in Quang Ninh province. A detailed description of this VA study are available elsewhere [24]. Complete VA interviews for 670 deaths that occurred between 1/1/ 2014 to $31 / 12 / 2014$ were successfully conducted, using a Vietnamese adapted version of international standard VA questionnaires. The adapted questionnaires have been used in a previous mortality surveillance project and some other studies in Vietnam [8, 25-27]. Interviewers were commune health workers and village health workers who received training in administering VA interviews. Multiple CODs and UCOD for each death were derived from completed VA questionnaires according to international standards and rules.

The VA questionnaire recorded the place of death, including the name of the hospital where death occurred. In case of deaths outside hospital, the questionnaire asked and recorded the last hospital attended during the terminal illness, and the interval (number of days and/or months) between hospital discharge and death.

Of 670 deaths in Quang Ninh province, cases which were included in the validation study needed to meet the following criteria:

1) Criterion 1: Deaths in hospitals. If the deceased did not die in a hospital/health facility then deaths within 30 days of discharge after last hospitalization (we assumed that the causes of death are very likely to be related to the discharge diagnosis and the information recorded in the MRs); and

2) Criterion 2: MRs for the deceased were available from the three hospitals which had the highest number of cases that satisfied criterion 1; and

3) Criterion 3: These MRs included documentation of the condition of the patient at discharge as "died" or "severe, the family wish to take the patient home".

\section{Identification of MRs and MR abstraction}

At first, the name, date of birth, sex and address were used to determine if the case found in the hospital database was the same as the case identified from the VA questionnaire. Subsequently, the complete MRs were retrieved from the archives, including documents from previous admissions in the same hospital. The MRs pertaining to the final admission were used as main source for MRs abstraction. The other records were reviewed to get additional information.

In each hospital, trained hospital nurses abstracted relevant details from the MRs onto a specific study data abstraction form (see Additional file 1). Accordingly, information about medical history of the patients, signs, symptoms, presenting illness and clinical events during hospitalization which culminated in either death or discharge of the patient, any relevant investigation results and diagnoses as well as laboratory tests performed were extracted onto the abstraction form.

\section{UCOD identification and coding}

In the next step, a senior trained physician with over 20 years of clinical experience reviewed the MRs abstracts and completed a Death Certificate (see Additional file 2) for each death, following the International Medical Certificate of cause of death format [28]. This form has two parts which allows 
documentation of the direct, antecedent and underlying causes of death to be recorded in part I and other conditions that may have contributed to the death to be recorded in part II. The completed death certificates then were coded by a senior trained coder using ICD-10 [29]. It is noted that all causes recorded in the death certificates were coded. Then the UCOD was assigned following the current international mortality coding rules [28]. According to the WHO standard definition, the UCOD is "the disease or injury which initiated the train of morbid events leading directly to death, or the circumstances of the accident or violence which produced the fatal injury" [28].

The accuracy of UCOD assignment was confirmed and reviewed by an independent expert coder using the most updated version of the Iris software (version 5) [30], using the "MUSE" function. The cause used for comparison for validating the VA was the UCOD. All people who participated in the data collection in hospitals, including the physician who reviewed the MRs abstraction and the ICD-10 coder, were blinded to the VA data to avoid information bias.

\section{Data management and analysis}

For efficiency in analyses, ICD codes for all COD were aggregated according to the WHO General Mortality Tabulation Condensed List I, comprising 103 categories of ICD-10 codes [31]. For assessing the validity of VA diagnoses, the UCOD identified from the MRs review were compared with the UCOD identified from the VA for each case. As a first step in the analysis, the percentage of agreement between underlying causes from MRs and VA were computed. Subsequently, we used the MRs diagnoses as the reference value to compute the sensitivity, specificity and positive predictive value (PPV) of the UCOD diagnosed from VA [19, 20, 22, 32-38]. Measures of validity were computed for conditions known to be among the leading causes of death in Vietnam [8]. We categorised validity as good if sensitivity was above $75 \%$, average if sensitivity lay between 50 to $75 \%$, and low if sensitivity is less than $50 \%$, similar to ratings used in other studies $[39,40]$. Standard errors were computed for these proportions, and used to develop 95\% confidence intervals for each of these values.

Validity of VA methods was also analysed by age of the deceased broadly categorized into 25-69 years and 70 and above. It is generally perceived that VA interviews are less informative for deaths in the elderly (i.e above 70 years), hence this age group analysis was undertaken to observe any variations in levels of validity for specific causes by age. In a subset of cases where the UCOD from VA did not match that from the MRs, we provided a descriptive summary of all reported COD from the MR.

\section{Results}

\section{Description of the study population}

The description of the selection of study population is shown in Fig. 1.

Of the 213 cases that were identified by the VA study to have been hospitalised in the three study hospitals, only 152 cases were found in the hospital records. Information on the status of patients on discharge (1-Recovered, 2Severe, the family wish to take the patient home, 3Referred, and 4-Died); and the date of admission and the date of discharge was reviewed. As part of this step, selection criterion 1 for the study sample was re-checked for all cases. It was found that there were 36 cases for which the MRs showed that they were discharged more than 30 days prior to the death, and hence these cases were excluded from the study sample. The total number of eligible cases for the validation study was therefore 116 deaths, accounting for only $54.5 \%$ of the initially extracted list (116/213). Table 1 shows more details of the study sample at each step of the selection process.

In our final study sample (116 cases), $70 \%$ of the deceased were male and $30 \%$ were female. Almost all were adult deaths with ages which ranged from 28 to 96 years old. About $45 \%$ of deaths were in the age group 70 years and older, $38 \%$ in the $50-69$ year age group and $16 \%$ in the age group of 25-49 years. There was a single oneyear-old child death which accounted for $0.9 \%$ of the sample. Only $5 \%$ of the deceased died in a hospital. 95\% of them were discharged in a severe condition and then died within 30 days at their home.

Figure 2 describes the duration of the interval from the date of the patient's discharge to the date of death. About $50 \%$ died on the same day as they were discharged from the hospital; 61\% died within 24 hours (one day); over $70 \%$ of patients died within three days; $76 \%$ of them died within 10 days after the family took them home.

\section{Validity of the UCOD from VA}

At first, we calculated the percentage agreement on UCOD between VA and the corresponding MRs. As can be seen in Table 2, there were about $57 \%$ of cases in which both sources assigned the same UCOD. There were 22 cases $(19 \%)$ in which the UCOD from VA was different to that from the MRs, but the condition recorded as the UCOD in the VA was one of the multiple causes recorded in the MRs.

To further understand the validity of the specific causes diagnosed by VA, sensitivity, specificity and PPV were calculated for leading causes. As presented in the Table 3, specificity scores were very high for all causes (from 91 to $100 \%$ ), which means VA is very good at not assigning a cause for a patient who really did not die of that cause. One possible reason for this high specificity is that for each cause, the number of true negatives from 


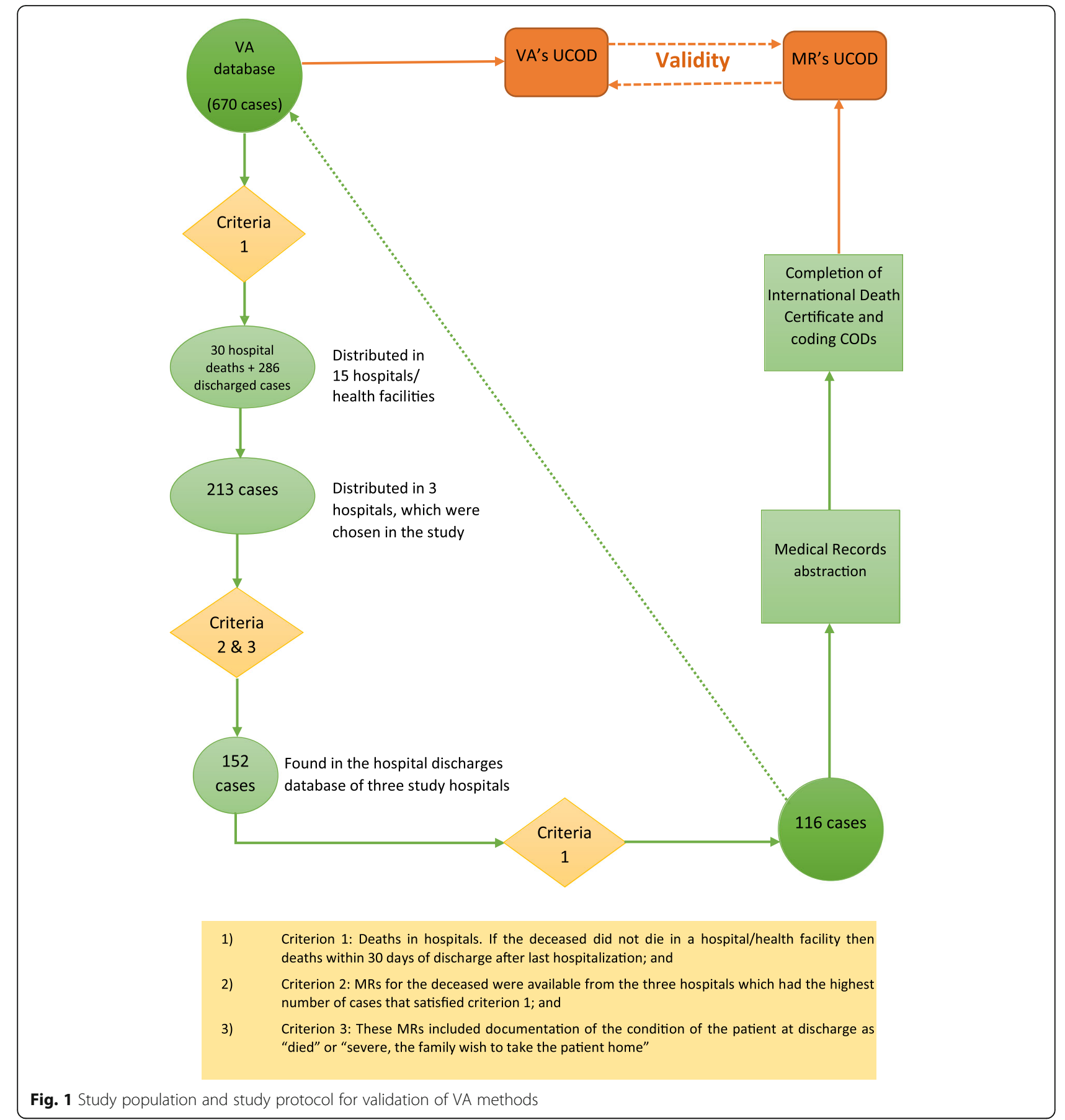

both sources of the study sample will always be high, owing to them being truly from other causes.

VA performed very well in diagnosing almost all major site-specific cancers (such as lung cancer, liver cancer, colon and rectum cancer) and road traffic accidents with scores of 75 to $100 \%$ for sensitivity and PPV. In the cardiovascular diseases group, the validity of VA varied among different causes. For stroke, sensitivity indicated that VA could capture nearly $80 \%$ of patients whose cause of death was actually stroke. However, the PPV indicates that VA tended to over-diagnose deaths due to stroke, with only $61 \%$ of VA diagnoses of stroke being confirmed by the MRs review.

Several other causes were also found to have low sensitivity (below 50\%). VA correctly diagnosed only 33\% deaths due to ischemic heart disease (IHD), 40\% deaths due to cirrhosis of liver, $40 \%$ deaths due to diabetes, $33 \%$ deaths due to pneumonia and only $14 \%$ deaths due to 
Table 1 Summary of the study sample by hospital

\begin{tabular}{lllll}
\hline Name of the hospital & $\begin{array}{l}\text { The initially extracted list } \\
\text { from VA database } \\
(\mathrm{n} 1)\end{array}$ & MRs found & Eligible cases & $\begin{array}{l}\text { Eligible cases compared to } \\
\text { the initially extracted list } \\
(\mathrm{n} / \mathrm{n} 1)\end{array}$ \\
\hline 1. Quang Ninh General hospital & 94 & $67 ; 71.3 \%$ & $51 ; 76.1 \%$ & $54.3 \%$ \\
2. Bai Chay district Hospital & 47 & $37 ; 78.7 \%$ & $32 ; 86.5 \%$ & $68.1 \%$ \\
3. Vietnam-Swiss Uong Bi Hospital & 72 & $48 ; 66.7 \%$ & $33 ; 68.8 \%$ & $45.8 \%$ \\
Total & 213 & $152 ; 71.4 \%$ & $116 ; 76.3 \%$ & $54.5 \%$ \\
\hline
\end{tabular}

COPD. We conducted a similar analysis of validity of VA diagnoses for age groups 25-69 and 70+ years. However, there was no difference between the two age groups regarding sensitivity, specificity and PPV scores for leading CODs (see Additional file 3).

As mentioned in Table 1, we found 19\% of cases where the UCOD from VA was one of causes listed on the MRs death certificate. We further analysed these 22 cases to better understand the misclassification patterns of underlying causes from VA, Table 4 presents information on multiple COD derived from available information in hospital MRs as well as from VA, according to the format of the international death certificate.

In about $32 \%(7 / 22)$ of cases, the UCOD from VA was either the direct cause or one of the antecedent causes identified from hospital MRs by the physician (cases 1, 2, $4,12,15,18$ and 22). The VA respondents for these cases might have only remembered the cause/conditions/signs which directly led to the death. For example, for case number 1 (Table 4), pneumonia was the direct cause which was a consequence of the UCOD, measles.
However, the VA respondent might not have reported the skin rash which is the only differentiating symptom indicative of measles as the underlying condition that caused pneumonia. Hence, based on the reported signs and symptoms, a diagnosis of pneumonia was derived, and this is a reasonable expectation of cause of death assignment from VA. Eventually, the identification of pneumonia by the VA in this case underscores the public health utility of this method for ascertaining causes of death. Table 4 also shows that in $68 \%$ of cases $(15 / 22)$ the UCOD from VA was a contributory cause recorded in Part II of the death certificate from the MRs. Most of these causes were noncommunicable diseases such as hypertensive diseases, diabetes mellitus, or stroke. These results also indicate the usefulness of VA in correctly identifying these major comorbidities, and hence justifying the value of VA in settings experiencing a growing epidemic of noncommunicable diseases, as in Vietnam. Therefore, establishing the validity of VA in determining such comorbidity through ascertaining multiple causes of death also adds value to the overall public health utility of VA.

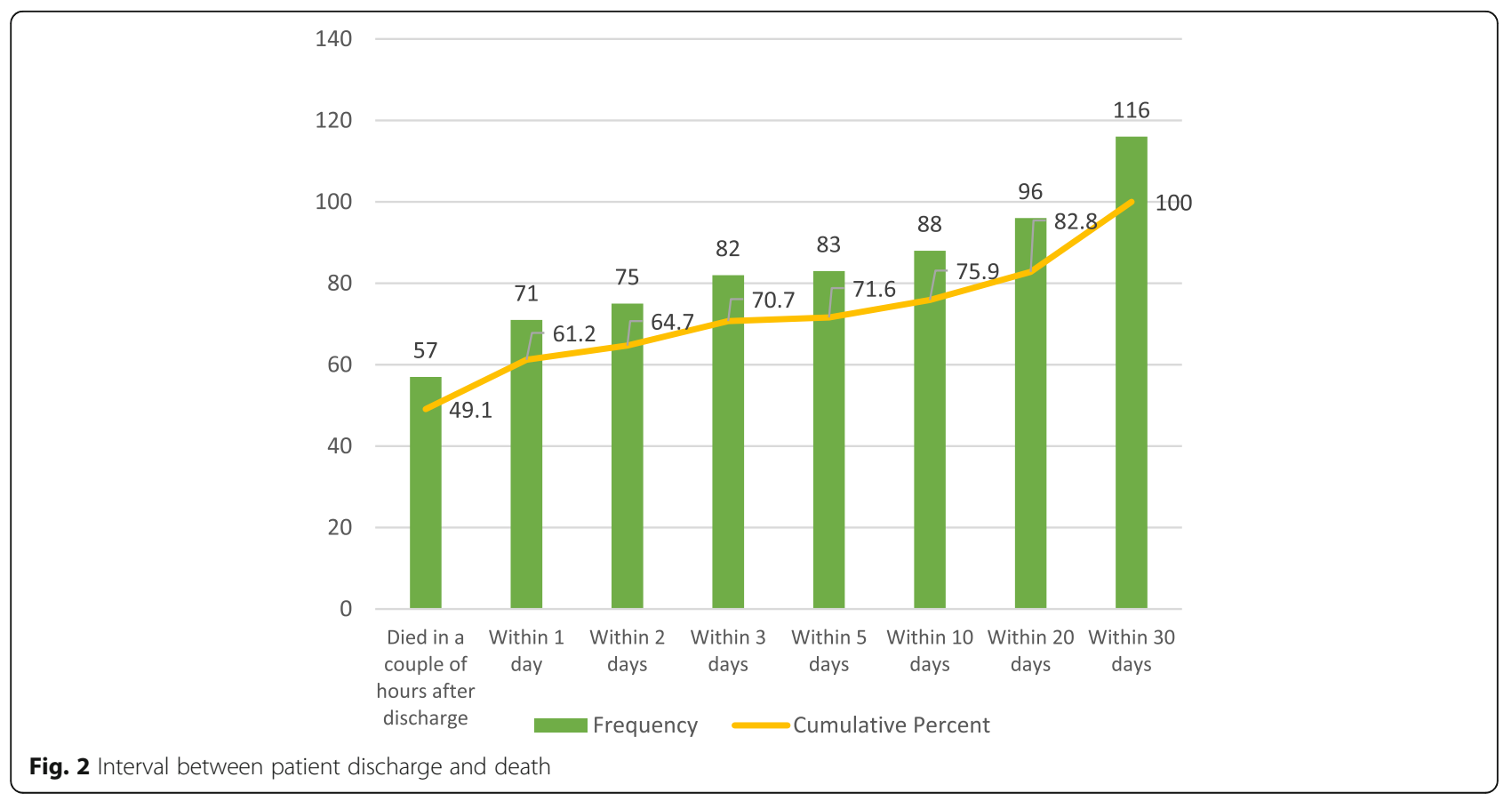


Table 2 Agreement on UCOD between VA and hospital MRs

\begin{tabular}{llll}
\hline & Age 25-69 (n; \%) & Age 70+ (n; \%) & Total $(n ; \%)$ \\
\hline UCOD from VA is the same as UCOD from MR & $38(60 \%)$ & $28(54 \%)$ & $66(57 \%)$ \\
UCOD from VA is one of multiple causes recorded in MR & $7(11 \%)$ & $14(27 \%)$ & $22(19 \%)$ \\
UCOD by VA is different from any cause in MR & $18(29 \%)$ & $63(19 \%)$ & $28(24 \%)$ \\
Total & 63 & 52 & 116 \\
\hline
\end{tabular}

\section{Discussion}

To our knowledge, this is the first known study to assess the validity of VA methods in Vietnam using hospital records to provide a diagnostic benchmark. Previous studies have identified the utility of VA for diagnosing deaths from stroke [11] and injuries [38], but did not employ specific comparison of VA diagnoses with reference standards in order to measure validity. Establishing the validity of VA methods is important when considering to use these methods on a routine basis to improve the availability and quality of mortality data in the country.

\section{The reference diagnosis}

Previous VA validation studies which have been conducted in other countries used the UCOD determined by physician review of hospital MRs of inpatient deaths as the reference diagnosis for validation [21, 22, 41, 42]. In Vietnam, VA methods are routinely used in three Demographic and Health Surveillance Systems and in a number of projects/studies to measure population level causespecific mortality. However, non-availability of a "gold standard" reference diagnosis for the underlying cause has been described as a constraint for the implementation of a

Table 3 Validity of the VA diagnosis on cause of death

\begin{tabular}{|c|c|c|c|c|c|c|c|c|}
\hline $\begin{array}{l}\text { Underlying cause } \\
\text { of death }\end{array}$ & ICD code & True positive & True negative & $\begin{array}{l}\text { Cases } \\
\text { diagnosed } \\
\text { from MRs }\end{array}$ & $\begin{array}{l}\text { Cases diagnosed } \\
\text { from VA }\end{array}$ & $\begin{array}{l}\text { Sensitivity, } \\
(95 \% \mathrm{Cl})\end{array}$ & $\begin{array}{l}\text { Specificity, } \\
(95 \% \mathrm{Cl})\end{array}$ & $\begin{array}{l}\text { PPV, } \\
(95 \% \mathrm{Cl})\end{array}$ \\
\hline \multicolumn{9}{|l|}{ Cancer } \\
\hline 1. Lung cancer & C34 & 8 & 108 & 8 & 8 & 100 & 100 & 100 \\
\hline 2. Liver cancer & $\mathrm{C} 22$ & 6 & 108 & 6 & 8 & 100 & $98(96-100)$ & $75(45-100)$ \\
\hline $\begin{array}{l}\text { 3. Colon and rectum } \\
\text { cancers }\end{array}$ & $\mathrm{C} 18-\mathrm{C} 21$ & 4 & 112 & 4 & 4 & 100 & 100 & 100 \\
\hline $\begin{array}{l}\text { 4. Mouth and oropharynx } \\
\text { cancers }\end{array}$ & $\mathrm{COO}-\mathrm{C} 14$ & 3 & 112 & 4 & 3 & $75(33-100)$ & 100 & 100 \\
\hline 5. Oesophagus cancer & $\mathrm{C} 15$ & 3 & 113 & 3 & 3 & 100 & 100 & 100 \\
\hline 6. Stomach cancer & $\mathrm{C} 16$ & 2 & 114 & 2 & 2 & 100 & 100 & 100 \\
\hline 7. Pancreas cancer & $\mathrm{C} 25$ & 2 & 114 & 2 & 2 & 100 & 100 & 100 \\
\hline \multicolumn{9}{|l|}{ Cadiovascular diseases } \\
\hline 8. Stroke & $160-169$ & 14 & 89 & 18 & 23 & 78 (59-97) & $91(85-97)$ & $61(41-81)$ \\
\hline 9. Ischaemic heart disease (IHD) & $120-125$ & 3 & 105 & 9 & 5 & $33(3-64)$ & $98(96-100)$ & $60(17-100)$ \\
\hline \multicolumn{9}{|c|}{ Other non-communicable diseases and external causes } \\
\hline 10. Diabetes mellitus & E10-E14 & 2 & 106 & 5 & 7 & $40(0-83)$ & $95(92-99)$ & $29(0-62)$ \\
\hline 11. Cirrhosis of liver & $\mathrm{K} 70, \mathrm{~K} 74$ & 2 & 110 & 5 & 3 & $40(0-83)$ & $99(97-100)$ & $67(13-100)$ \\
\hline $\begin{array}{l}\text { 12. Chronic obstructive } \\
\text { pulmonary diseases (COPD) }\end{array}$ & J40-J44 & 1 & 109 & 7 & 1 & $14(0-40)$ & 100 & 100 \\
\hline 13. Road traffic Injury & $\begin{array}{l}\text { V01-V04, V06, } \\
\text { V09-V80, V87, } \\
\text { V89, V99 }\end{array}$ & 4 & 112 & 4 & 4 & 100 & 100 & 100 \\
\hline \multicolumn{9}{|l|}{ Communicable diseases } \\
\hline 14. HIV/AIDS & B20-B24 & 2 & 113 & 3 & 2 & $67(13-100)$ & 100 & 100 \\
\hline 15. Pneumonia & $J 12-J 18$ & 2 & 102 & 6 & 10 & $33(0-71)$ & $93(88-98)$ & $20(0-45)$ \\
\hline Other causes & & 8 & & 30 & 31 & & & \\
\hline Total & & 66 & & 116 & 116 & & & \\
\hline
\end{tabular}


Table 4 Description of multiple causes of death for 22 cases

\begin{tabular}{|c|c|c|c|c|c|c|c|c|c|c|c|c|c|}
\hline Case & MR_UCOD & MR_la & MR_lb & MR_Ic & MR_Id & MR_II.1 & MR_\|l.2 & MR $\| 3$ & MR $\| 4$ & VA_UCOD & VA_la & VA_\|1 & VA_॥2 \\
\hline & Measles & Pneumonia & Measles & & & & & & & Pneumonia & $\begin{array}{l}\text { Ressiratory } \\
\text { fialure }\end{array}$ & & \\
\hline 2 & Virat hepatitis & $\begin{array}{l}\text { Diseases of digestive } \\
\text { system }\end{array}$ & Liver diseases & Vira hepatitis & & & & & & Liver diseases & $\begin{array}{l}\text { Respiritory } \\
\text { fisure }\end{array}$ & & \\
\hline 3 & Vira hepattis & Liver diseases & Liver diseases & $\begin{array}{l}\text { Diseases of digestive } \\
\text { system }\end{array}$ & $\begin{array}{l}\text { Viral } \\
\text { hepatitis }\end{array}$ & Pneumonia & & Fall & & Fall & $\begin{array}{l}\text { Intractranial } \\
\text { Injury }\end{array}$ & & \\
\hline 4 & HIV & Respiratory failure & Pneumonia & HIV & & & & & & Pneumonia & & Diabetes & \\
\hline 5 & $\begin{array}{l}\text { Lip, oral cavity and } \\
\text { pharnnx cancer }\end{array}$ & Respiratory failure & $\begin{array}{l}\text { Other cancer } \\
\text { (secondary cancer) }\end{array}$ & $\begin{array}{l}\text { Lip, oral cavity and } \\
\text { pharynx cancer }\end{array}$ & & \begin{tabular}{|l|}
$\begin{array}{l}\text { Other heart } \\
\text { diseases }\end{array}$ \\
\end{tabular} & & & & $\begin{array}{l}\text { Other heart } \\
\text { diseases }\end{array}$ & & & \\
\hline 6 & Leukaemia & Pneumonia & Leukaemia & & & $\begin{array}{l}\text { Hyyertensive } \\
\text { diseases }\end{array}$ & COPD & & & 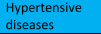 & & & \\
\hline 7 & $\begin{array}{l}\text { Icchamemich hart } \\
\text { diseases }\end{array}$ & coma & $\begin{array}{l}\text { Ischamemic heart } \\
\text { disiseases }\end{array}$ & & & $\begin{array}{l}\text { Hypertensive } \\
\text { diseases }\end{array}$ & Diabetes & & & Diabetes & & & \\
\hline 8 & $\begin{array}{l}\text { Ischaemic heart } \\
\text { disisases }\end{array}$ & $\begin{array}{l}\text { Ischemic heart } \\
\text { diseases }\end{array}$ & & & & $\begin{array}{l}\text { Hypertensive } \\
\text { disisases }\end{array}$ & $\begin{array}{l}\text { other external } \\
\text { causes }\end{array}$ & $\begin{array}{l}\text { Diseases of } \\
\text { digigstiv system }\end{array}$ & & 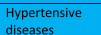 & & & \\
\hline 9 & $\begin{array}{l}\text { Ischaemic heart } \\
\text { diseases }\end{array}$ & coma & $\begin{array}{l}\text { Ischemic heart } \\
\text { diseases }\end{array}$ & & & $\begin{array}{l}\text { Hypertensive } \\
\text { diseases }\end{array}$ & Other heart diseases & $\begin{array}{l}\text { Disenseseof } \\
\text { gentiournary } \\
\text { system (Renal } \\
\text { failure) }\end{array}$ & & 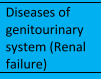 & & & \\
\hline 10 & Stroke & coma & Stroke & & & Pneumonia & 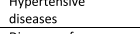 & Diabetes & & Pneumonia & & Diabetes & \\
\hline 11 & Stroke & Stroke & & & & \begin{tabular}{|l}
$\begin{array}{l}\text { Hypertensive } \\
\text { disseases }\end{array}$ \\
\end{tabular} & $\begin{array}{l}\text { Diseases of } \\
\text { genintourinary system } \\
\text { (Renal failure) }\end{array}$ & Other neoplasms & $\begin{array}{l}\text { Inflammatory } \\
\text { polyarthropathies }\end{array}$ & $\begin{array}{l}\text { Inflammatotry } \\
\text { polyarthropathi } \\
\text { es }\end{array}$ & $\begin{array}{l}\text { Respiratory } \\
\text { falure }\end{array}$ & & \\
\hline 12 & $\begin{array}{l}\text { Otther riseasese of } \\
\text { circulatory system } \\
\text { (abdominal aortic } \\
\text { aneurrysm) }\end{array}$ & Respiratory failure & $\begin{array}{l}\text { Ischamemich hart } \\
\text { diseases }\end{array}$ & $\begin{array}{l}\text { Other riseasese of } \\
\text { circulatory system } \\
\text { (abdominal aortic } \\
\text { aneurysm) }\end{array}$ & & $\begin{array}{l}\text { Hypertensive } \\
\text { diseases }\end{array}$ & & & & $\begin{array}{l}\text { Icchemic heart } \\
\text { diseases }\end{array}$ & & $\begin{array}{l}\text { Hypertensive } \\
\text { diseases }\end{array}$ & \\
\hline 13 & COPD & Respiratory failure & Pneumonia & COPD & & \begin{tabular}{|l} 
Hypertensive \\
diseases
\end{tabular} & Diabetes & & & Diabetes & & \begin{tabular}{|l|}
$\begin{array}{l}\text { Hypertensive } \\
\text { diseases }\end{array}$ \\
\end{tabular} & \\
\hline 14 & COPD & Respiratory failure & COPD & & & $\begin{array}{l}\text { Diabetes } \\
\end{array}$ & Stroke & 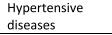 & & Stroke & & $\begin{array}{l}\text { Hypertensive } \\
\text { diseases }\end{array}$ & Diabetes \\
\hline 15 & COPD & $\begin{array}{l}\text { Ischemic heart } \\
\text { diseases }\end{array}$ & Other heart diseases & Pneumonia & COPD & & & & & Pneumonia & & & \\
\hline 16 & $\begin{array}{l}\text { Crronic lower } \\
\text { respiritory } \\
\text { diseases (status } \\
\text { asthmaticus) } \\
\end{array}$ & Respiratory failure & $\begin{array}{l}\text { Chronic lower } \\
\text { respiratory diseases } \\
\text { (status asthmaticus) }\end{array}$ & & & Diabetes & & & & Diabetes & & & \\
\hline 17 & $\begin{array}{l}\text { Disigasese of } \\
\text { digestive system }\end{array}$ & $\begin{array}{l}\text { Disisases of digestive } \\
\text { system }\end{array}$ & $\begin{array}{l}\text { Disisases of digestive } \\
\text { system }\end{array}$ & & & Pneumonia & & & & Pneumonia & & & \\
\hline 18 & Liver diseases & $\begin{array}{l}\text { Diseases of } \\
\text { ressiritory system }\end{array}$ & Pneumonia & Liver diseases & & & & & & $\begin{array}{l}\text { Diseases of } \\
\text { respratory }\end{array}$ & & & \\
\hline 19 & Liver diseases & Liver diseases & Liver diseases & & & \begin{tabular}{|l|}
$\begin{array}{l}\text { Hypertensive } \\
\text { diseases }\end{array}$ \\
\end{tabular} & Stroke & & & Stroke & Cachexia & \begin{tabular}{|l|}
$\begin{array}{l}\text { Hypertensive } \\
\text { diseases }\end{array}$ \\
\end{tabular} & \\
\hline 20 & Fall & Coma & Fracture of femur & Fall & & $\begin{array}{l}\text { Hypertensive } \\
\text { diseases }\end{array}$ & Pneumonia & Stroke & & Stroke & & $\begin{array}{l}\text { Hypertensive } \\
\text { diseases }\end{array}$ & \\
\hline 21 & 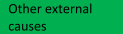 & Respiratory failure & Pneumonia & 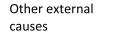 & & Diabetes & & & & Diabetes & & & \\
\hline 2 & Sepsis & $\begin{array}{l}\text { Fever (IIt-defined } \\
\text { conotion) }\end{array}$ & $\begin{array}{l}\text { Diseases of digestive } \\
\text { system }\end{array}$ & Sepsis & & \begin{tabular}{|l} 
Hypertensive \\
diseases
\end{tabular} & & & & $\begin{array}{l}\text { Fever (rII- } \\
\text { defind } \\
\text { condition) }\end{array}$ & & & \\
\hline
\end{tabular}

MR_UCOD is the underlying COD derived from information in MR. MR_la is the MR's COD recorded in Part I(a) of death certificate. MR_lb is the MR's COD recorded in Part I(b). Similar to MR Ic and MR Id. MR II.1, MR II.2, MR II.3, MR II.4 are the MR's COD recorded in the part II of death certificate. VA UCOD is the underlying COD by VA. VA_la is the VA's COD recorded in Part I (a). Similar explanation for VA_Il.1 and VA_Il.2. The "green data" indicated the UCOD which was assigned base on MRs while the "blue data" indicated the UCOD which was assigned base on VA methods. Some "blue data" was highlighted in other selected cells inside the table, which indicates that the cause/condition assigned as UCOD from VA is one of causes recorded in MRs (but not UCOD)

validation study [19]. This study demonstrated a potential solution for overcoming this constraint in the Vietnam context. In designing this study, we first noted that from the VA database of 670 deaths in Quang Ninh province, we found only 30 cases (about 5\%) who died in a hospital/ health facility. However, about $70 \%$ of the deceased had been hospitalised during their terminal illness [24]. Hence, we chose to use the MRs of patients who had been discharged from hospital within 30 days prior their death, as the source for reference diagnoses to validate the COD from VA.

\section{Validity of VA and potential for its improvement}

In this study we found that for the UCOD comparison across all cases, there was $57 \%$ agreement between VA and physician review of hospital MRs. This percentage of agreement on cause-specific codes is much higher than found in a study conducted in Malawi, which reported only $26.2 \%$ agreement [41]. When taking into account the comparison across multiple causes, the underlying cause from VA matched with one of the multiple causes in the MRs in $76 \%$ of cases. These overall findings confirmed the value of VA methods in identifying the COD for deaths which occur outside hospitals in Vietnam.
Despite these high levels of agreement as well as good sensitivity scores for some causes of death, the relatively lower sensitivity of VA UCOD diagnoses for several important conditions including ischaemic heart disease, COPD, diabetes and pneumonia is a cause for concern. Similar findings of low sensitivity scores $(<50 \%)$ for these specific causes of death have also been observed in other verbal autopsy validation studies in China $[19,40]$, Malaysia [43] and Thailand [42]. To some extent, the analysis of multiple causes of death as presented in Table 4 has improved our understanding of misclassification patterns that result in low sensitivity scores for these conditions as underlying causes. In view of the potential for several of these conditions to be co-existent in many instances, the tools and processes employed for VA data collection, diagnosis and coding should routinely facilitate the reporting and analysis of multiple causes. While this would enhance the utility of VA data for both descriptive and analytical epidemiology, multiple cause analysis will also strengthen the assessment of validity of VA diagnoses in future studies.

Obtaining medical records or at least discharge diagnoses for terminally ill patients could be an important source of information to strengthen cause of death 
ascertainment for such events. Such information is particularly relevant for conditions that need specific clinical diagnostic tests or imaging investigations. If every discharged patient is provided with a discharge summary relating to their hospitalisation, this would provide valuable information for ascertaining the COD, in the case of a VA interview. The interviewers could ask the family member to show those documents and therefore important information may be obtained.

\section{Limitations}

A key limitation of this study is the small sample size which resulted in the large ranges of $95 \% \mathrm{CI}$ of sensitivity and PPV values for specific causes. The small sample size critically hampers more detailed analysis of validity for a wider range of causes, as well as for any variations in cause-specific validity across gender and rural/urban areas. To start with, the initial sampling frame for this study was limited to the sample of deaths associated with selected hospitals from one province, owing to restrictions in terms of costs, manpower, and other logistical factors. Further, as mentioned previously, there were losses to follow up during the study implementation. For instance, only $71.4 \%$ of the 213 eligible cases reported in the VA study to have accessed treatment from the three hospitals were actually traced in the hospital records. The remaining $28.6 \%$ cases could not be matched according to the full name, sex, date of birth and address of the deceased. There are probably two reasons for this phenomenon. The first may be the issue of misinformation or miscommunication of relevant identification details by the patient (or the patient's relatives) with the hospital's administration/reception at admission. In many cases in Vietnam, the elderly live with their children in another province, the hospital may record their current address, while the VA records their original home address [8], resulting in a mismatch. The second reason may due to incorrect information in the VA interview in response to the question on last treatment accessed before death. In some instances, individuals receive treatment as an outpatient in several different clinics or hospitals for the same illness, and at the VA interview, the deceased's relative might have provided an incorrect health facility name as the site for last hospitalization.

There was an additional 24\% (36 cases) of cases that were excluded since the actual date of hospitalization reported at the VA interview was incorrect. These individuals had actually been discharged more than 30 days prior to death, and hence had to be dropped from the study. Eventually, the final number of 116 study cases accounted for only $55 \%$ of the 213 cases in the initial extracted list. These losses to follow up further limited the study sample size but were considerably less than the $75 \%$ losses observed in a validation study which was conducted in
Ethiopia with a similar approach to trace medical records of community reported deaths in hospital records [21]. Such potential losses to study samples and the reasons for the same should be anticipated in establishing the study design and sample size for future VA validation studies in Vietnam and other similar settings.

A potential limitation of the approach to use hospital discharge records as a data source for ascertaining causes of death is that there may be cause(s) other than the discharge diagnosis that could have resulted in the death. The potential for such instances would increase with the length of the interval between discharge and death. Further research evidence would be required to identify the most suitable cut-off time for the use of reference diagnoses from the medical records for discharged patients in VA validation studies.

\section{Conclusion}

Our findings suggest that VA is a valid method to ascertain UCOD in contexts such as Vietnam. Furthermore, within cultural contexts in which patients prefer to die at home instead of a healthcare facility, using the available MRs as the gold standard may be meaningful to the extent that recall bias from the interval between last hospital discharge and death can be minimized. Therefore, future studies should evaluate validity of MRs as a gold standard for VA studies in contexts similar to the Vietnamese context.

\section{Additional files}

Additional file 1: Medical record abstraction form. This supplementary document provides the form which was used to abstract information from medical records. (PDF $215 \mathrm{~kb}$ )

Additional file 2: Death Certificate. This supplementary document provides the International form of medical certificate of cause of death. (PDF 266 kb)

Additional file 3: Validity by age groups. This supplementary document included two tables which describe the calculation of validity of the VA diagnosis on causes of death by age 25-69 years and 70+ years. (PDF $82 \mathrm{~kb}$ )

\section{Abbreviations}

COD: Causes of death; CRVS: Civil registration and vital statistics; DHSSs: Demographic health surveillance systems; IHD: Ischemic heart diseases; MRs: Medical records; UCOD: Underlying cause of death; VA: Verbal autopsy

\section{Acknowledgements \\ We would like to thank hospital directors and staff of Department of General Planning, Information Technology division, and Medical Record devision in three study hospitals (Quang Ninh General Hospital, Bai Chay hospital and Vietnam-Swiss Uong Bi hospital) for their great support during data collection from hospital medical records for this study. We acknowledge Centers for Disease Control and Prevention (CDC), Viet Nam for their comments and financial support to conduct the VA study in Quang Ninh province.}

Availability of data and materials

All data generated or analysed during this study are included in this published article and its supplementary information files. 


\section{Authors' contributions}

HTT designed and conceptualized the study. CR and HPN gave significant comments on study design. HTT organized and supervised data collection at the field. HTT, HPN and SW worked on data processing. HTT analysed the data. HTT interpreted the results and wrote the first draft of the article. CR and PSH made significant contribution on method and discussion sections. All authors contributed to critical revision of the manuscript for important intellectual content, and read and approved the final manuscript.

\section{Ethics approval and consent to participate}

Ethical approval for this study was obtained from the Institutional Review Board of Ha Noi Medical University, Vietnam (reference number 173/HMU-IRB) and the University of Queensland, Australia (reference number THT23062015). All personal information in the medical records was used only for study purposes and only accessed by the principal investigator for linkage with the VA database. It was then de-identified before data entry and data analysis.

\section{Competing interests}

All authors declare no conflicts of interest in this paper. The authors have not received any funding or benefits from industry or elsewhere to write this paper.

\section{Publisher's Note}

Springer Nature remains neutral with regard to jurisdictional claims in published maps and institutional affiliations.

\begin{abstract}
Author details
${ }^{1}$ Faculty of Fundamental Sciences, Hanoi University of Public Health, Hanoi, Vietnam. ${ }^{2}$ School of Public Health, University of Queensland, Brisbane, Australia. ${ }^{3}$ Family Medicine Department, Hanoi Medical University, Hanoi, Vietnam. ${ }^{4}$ School of Public Health and Social Work, Queensland University of Technology, Brisbane, Australia. ${ }^{5}$ National Centre for Health Information Research and Training, Queensland University of Technology, Brisbane, Australia. ${ }^{6}$ Department of Global Health, Research School of Population Health, ANU College of Health and Medicine, Australian National University, Canberra, Australia.
\end{abstract}

\section{Received: 26 July 2017 Accepted: 30 April 2018} Published online: 18 May 2018

\section{References}

1. The 2016 WHO verbal autopsy instrument. http://www.who.int/healthinfo/ statistics/verbalautopsystandards/en/. Accessed 6 May 2018.

2. Editorial. Towards 2030: counting and accountability matter. Lancet. 2015; 386(10001):1312

3. Verbal Autopsy Standard: The 2014 WHO verbal autopsy instrument. http://www.who.int/healthinfo/statistics/verbalautopsystandards/en/. Accessed 6 May 2018

4. Fottrell E, Byass P. Verbal Autosy: methods in transition. Epidemiol Rev. 2010;32:8.

5. World health statistics 2017: monitoring health for the SDGs, Sustainable Development Goals. http://apps.who.int/iris/bitstream/10665/255336/1/ 9789241565486-eng.pdf?ua=1. Accessed 6 May 2018.

6. Rao C, Osterberger B, Anh TD, MacDonald M, Chuc NT, Hill PS. Compiling mortality statistics from civil registration systems in Vietnam: the long road ahead. Bull World Health Organ. 2010;88(1):58-65.

7. Lanh LT. The current situation of birth and death reporting system by Ministry of Justice. In: National Conference on health management information system: 2012; Hanoi, Vietnam; 2012. p. 9.

8. Hoa NP, Rao C, Hoy DG, Hinh ND, Chuc NT, Ngo DA. Mortality measures from sample-based surveillance: evidence of the epidemiological transition in Vietnam. Bull World Health Organ. 2012;90(10):764-72.

9. D'Ambruoso L, Boerma T, Byass P, Fottrell E, Herbst K, Källander K, Mullan Z. The case for verbal autopsy in health systems strengthening. Lancet Glob Health. 2017;5(1):e20-1.

10. de Savigny D, Riley I, Chandramohan D, Odhiambo F, Nichols E, Notzon S, AbouZahr C, Mitra R, Cobos Munoz D, Firth S, et al. Integrating communitybased verbal autopsy into civil registration and vital statistics (CRVS): systemlevel considerations. Glob Health Action. 2017;10(1):1272882.

11. Gupta S, Khieu TQ, Rao C, Anh N, Hoa NP. Assessing the quality of evidence for verbal autopsy diagnosis of stroke in Vietnam. J Neurosci Rural Pract. 2012;3(3):267-75.
12. Quyen BTT, Cuong PV. Patterns of mortality in elderly in chi Linh, Hai Duong, Vietnam period 2004-2012. AIMS Public Health. 2016;3(3):615-28.

13. Sankoh $O$, Byass $P$. The INDEPTH network: filling vital gaps in global epidemiology. Int J Epidemiol. 2012:41(3):579-88.

14. Rao C. Mortality estimates for South East Asia, and INDEPTH mortality surveillance: necessary but not sufficient? Int J Epidemiol. 2013;42(4):1196-9.

15. Tran BH, Nguyen HT, Ho HT, Pham CV, Le VT, Le AV. The chi Linh health and demographic surveillance system (CHILILAB HDSS). Int J Epidemiol. 2013;42(3):750-7.

16. Tran TK, Eriksson B, Nguyen CT, Horby P, Bondjers G, Petzold M. DodaLab: an urban health and demographic surveillance site, the first three years in Hanoi, Vietnam. Scand J Public Health. 2012;40(8):765-72.

17. Huong DL, Minh HV, Byass P. Applying verbal autopsy to determine cause of death in rural Vietnam. Scand J Public Health Suppl. 2003;62:19-25.

18. Stevenson M, Hung DV, Hoang TH, Mai Anh L, Nguyen Thi Hong T, Le Tran $\mathrm{N}$. Evaluation of the Vietnamese A6 mortality reporting system: all-cause mortality. Asia Pac J Public Health. 2015;27(7):733-42.

19. Yang G, Rao C, Ma J, Wang L, Wan X, Dubrovsky G, Lopez AD. Validation of verbal autopsy procedures for adult deaths in China. Int J Epidemiol. 2006;35(3):741-8.

20. Chandramohan D. Validation and validity of verbal autopsy procedures. Popul Health Metr. 2011;9:22

21. Misganaw A, Mariam DH, Araya T, Aneneh A. Validity of verbal autopsy method to determine causes of death among adults in the urban setting of Ethiopia. BMC Med Res Methodol. 2012;12:130.

22. Soofi SB, Ariff S, Khan U, Turab A, Khan GN, Habib A, Sadiq K, Suhag Z, Bhatti Z, Ahmed I, et al. Diagnostic accuracy of WHO verbal autopsy tool for ascertaining causes of neonatal deaths in the urban setting of Pakistan: a hospital-based prospective study. BMC Pediatr. 2015;15:144.

23. Department of Medical Services Administration. Summary statistics from hospital routine reporting system. Hanoi: Vietnamese Ministry of Health; 2017.

24. Hong TT, Phuong Hoa N, Walker SM, Hill PS, Rao C. Completeness and reliability of mortality data in Vietnam: implications for the national routine health management information system. PLoS One. 2018;13(1):e0190755.

25. Ngo AD, Rao C, Hoa NP, Adair T, Chuc NT. Mortality patterns in Vietnam, 2006: findings from a national verbal autopsy survey. BMC Res Notes. 2010;3:78.

26. Ngo AD, Rao C, Hoa NP, Hoy DG, Trang KT, Hill PS. Road traffic related mortality in Vietnam: evidence for policy from a national sample mortality surveillance system. BMC Public Health. 2012;12:561.

27. Chuc NTK, Hoa NP, Rao C, Anh ND. Xác định nguyên nhân tử vong qua phỏng vấn: Tài liệu tập huấn dành cho điều tra viên (Identification of cause of death using interview: Training document for interviewers). Hanoi: Medical Publishing House; 2011.

28. International statistical classification of diseases and related health problems. 10th revision. Volume 2 - Instruction manual. Fifth edition. http://apps.who.int/ classifications/icd10/browse/Content/statichtml/ICD10Volume2_en_2016.pdf. Accessed 6 May 2018.

29. International Statistical Classification of Diseases and Related Health Problems 10th Revision. Volume 1. Online version: http://apps.who.int/ classifications/icd10/browse/2016/en. Accessed 6 May 2018.

30. Iris software. Version 5. http://www.dimdi.de/static/en/klassi/irisinstitute/about-iris/ index.htm. Accessed 6 May 2018.

31. WHO. International statistical classification of diseases and related health problems 10th revision. Volume 1- tabular list. Fifth edition. Geneva: WHO Press; 2016.

32. Chandramohan D, Maude GH, Rodrigues LC, Hayes RJ. Verbal autopsies for adult deaths: issues in their development and validation. Int J Epidemiol. 1994;23(2):213-22

33. Aggarwal AK, Kumar P, Pandit S, Kumar R. Accuracy of WHO verbal autopsy tool in determining major causes of neonatal deaths in India. PLoS One. 2013;8(1):e54865.

34. Khademi $H$, Etemadi A, Kamangar F, Nouraie M, Shakeri R, Abaie B, Pourshams A, Bagheri M, Hooshyar A, Islami F, et al. Verbal autopsy: reliability and validity estimates for causes of death in the Golestan cohort study in Iran. PLoS One. 2010:5(6):e11183.

35. Mpimbaza A, Filler S, Katureebe A, Kinara SO, Nzabandora E, Quick L, Ratcliffe A, Wabwire-Mangen F, Chandramohan D, Staedke SG. Validity of verbal autopsy procedures for determining malaria deaths in different epidemiological settings in Uganda. PLoS One. 2011;6(10):e26892.

36. Ganapathy SS, Khoo YY, Azahadi MO, Fuad MAM, Jeevananthan C, Rao C. Validation of verbal autopsy: determination of cause of deaths in Malaysia 2013. BMC Public Health. 2017;17:653. 
37. Murray CJ, Lozano R, Flaxman AD, Serina P, Phillips D, Stewart A, James SL, Vahdatpour A, Atkinson C, Freeman MK, et al. Using verbal autopsy to measure causes of death: the comparative performance of existing methods. BMC Med. 2014;12:5.

38. Stevenson MR, Ngoan le T, Hung DV, Huong Tu NT, Mai AL, Ivers RQ, Huong HT. Evaluation of the Vietnamese A6 mortality reporting system: injury as a cause of death. Inj Prev. 2012;18(6):360-4.

39. Moriyama IM, Baum WS, Haenszel WM, Mattison BF. Inquiry into diagnostic evidence supporting medical certifications of death. Am J Public Health Nations Health. 1958;48(10):1376-87.

40. Rao C, Yang G, Hu J, Ma J, Xia W, Lopez AD. Validation of cause-of-death statistics in urban China. Int J Epidemiol. 2007;36(3):642-51.

41. Qureshi JS, Samuel JC, Mulima G, Kakoulides S, Cairns B, Charles AG. Validating a verbal autopsy tool to assess pre-hospital trauma mortality burden in a resource-poor setting. Tropical Med Int Health. 2014;19(4):407-12.

42. Polprasert W, Rao C, Adair T, Pattaraarchachai J, Porapakkham Y, Lopez AD. Cause-of-death ascertainment for deaths that occur outside hospitals in Thailand: application of verbal autopsy methods. Popul Health Metr. 2010;8:13.

43. Omar A, Yi K, Fuad M, Ganapathy S, Jeevananthan C, Yusoff AF, Mustaffa AN, Rao C: A study on determination of causes of death in Malaysia. A report published by the Institute of Public Health, Ministry of Health, Malaysia. ISBN: 978-983-2387-32-9. 2017. Pgs. 1-167. 2017.

Ready to submit your research? Choose BMC and benefit from:

- fast, convenient online submission

- thorough peer review by experienced researchers in your field

- rapid publication on acceptance

- support for research data, including large and complex data types

- gold Open Access which fosters wider collaboration and increased citations

- maximum visibility for your research: over $100 \mathrm{M}$ website views per year

At BMC, research is always in progress.

Learn more biomedcentral.com/submissions 